\title{
APLICAÇÃO DA ABORDAGEM STEAM ATRAVÉS DE PROJETO INTERDISCIPLINAR SOBRE A PANDEMIA DA COVID-19
}

\author{
Tatiane Maria da Silva Dias ${ }^{1}$, Geison Jader Mello ${ }^{2}$
}

${ }^{1}$ Mestranda em Ensino - Instituto Federal de Educação, Ciência e Tecnologia de Mato Grosso IFMT, Campus Cuiabá Cel. Octayde Jorge da Silva, Cuiabá-MT, Brasil.

${ }^{2}$ Doutor em Física Ambiental, Programa de Pós-Graduação em Ensino, PPGEn, Instituto Federal de Educação, Ciência e Tecnologia de Mato Grosso, IFMT.

E-mail: geison.mello@cba.ifmt.edu.br

\section{Recebido em: 15/11/2021 - Aprovado em: 15/12/2021 - Publicado em: 30/12/2021 DOI: 10.18677/EnciBio_2021D5}

trabalho licenciado sob licença Creative Commons Attribution-NonCommercial-NoDerivatives 4.0 International License.

\begin{abstract}
RESUMO
O ensino a partir da Abordagem STEAM (Ciências, Tecnologia, Engenharia, Artes e Matemática) baseada em projetos vislumbra uma educação ativa na qual o estudante é instigado a ser protagonista e resolver situações problemas de sua comunidade. O desenvolvimento destas competências e habilidades, mais especificamente na área das Ciências da Natureza estão presentes na Base Nacional Comum Curricular (BNCC) e no Documento de Referência Curricular do Estado de Mato Grosso (DRC-MT). Neste sentido, o objetivo deste artigo foi desenvolver um projeto interdisciplinar nos anos finais do Ensino Fundamental em uma escola pública a partir da Abordagem STEAM. A metodologia utilizada foi a abordagem qualitativa com características de pesquisa exploratória. Os colaboradores da pesquisa foram professores e estudantes de uma escola pública localizada no município de Jauru - MT. A coleta de dados foi realizada através da observação participante durante a elaboração e execução das ações do projeto intitulado: Pandemia da COVID-19. Os resultados demonstraram que, quando desafiados, os estudantes constroem seu conhecimento, desenvolvendo competências e habilidades através da investigação, ideação e prototipagem, como mencionado nas premissas da Abordagem STEAM.
\end{abstract}

PALAVRAS-CHAVE: BNCC, Ensino Fundamental, Interdisciplinaridade

\section{APPLICATION OF THE STEAM APPROACH THROUGH AN INTERDISCIPLINARY PROJECT ON THE COVID-19 PANDEMIC}

\begin{abstract}
Teaching from the STEAM Approach (Science, Technology, Engineering, Arts and Mathematics) based on projects aims at an active education to which the student is encouraged to be protagonists and solve problematic situations in their community. Or the development of these skills and abilities, more specifically in the area of Natural Sciences, are present in the Common National Curriculum Base (BNCC) and no Curriculum Reference Document of the State of Mato Grosso (RDC-MT). In this sense, or objective of this article was to develop an interdisciplinary project in the
\end{abstract}


final years of Elementary School in a public school based on the STEAM Approach. The methodology used was a qualitative approach with exploratory research characteristics. Research collaborators for teachers and students of a public school located in the city of Jauru - MT. Data collection was carried out through participant observation during the elaboration and execution of the actions of the project entitled: COVID-19 Pandemic. The results show that, when challenged, students build their knowledge, developing skills and abilities through research, ideation and prototyping, as mentioned in the premises of the STEAM Approach.

KEYWORDS: BNCC, Elementary School, Interdisciplinarity

\section{INTRODUÇÃO}

A interdisciplinaridade é a integração e o engajamento de professores em um trabalho conjunto através da interação entre os componentes curriculares e a realidade vivenciada pelos estudantes, visando a superação da fragmentação do ensino (LÜCK, 2013). Para desenvolver atividades interdisciplinares é necessário diálogo, abertura por parte dos envolvidos e atitude colaborativa no processo de investigação e conhecimento em conjunto, visando a construção de um trabalho coletivo realizado a partir de trocas recorrentes e recíprocas (SOUSA; PINHO, 2017).

O trabalho interdisciplinar pode ser desenvolvido por diversas áreas do conhecimento e ainda por abordagens curriculares, como a STEAM, acrônimo de Ciências, Tecnologia, Engenharia, Arte e Matemática (BACICH; HOLANDA, 2020). A Abordagem STEAM baseada em projetos possui elementos da interdisciplinaridade, o que favorece as experiências de aprendizagem contribuindo para que os estudantes consigam atingir os objetivos propostos de forma crítica, reflexiva e participativa, através da resolução de problemas reais (BACICH; HOLANDA, 2020).

Para Fazenda (2010), o trabalho através de projetos interdisciplinares, por ser um método ativo, favorece o protagonismo estudantil, pois respeita os saberes dos estudantes em sua integração. Os currículos organizados através dos componentes curriculares tradicionais conduzem o estudante a um acúmulo de informações pouco significativo em sua vida profissional, especialmente porque 0 desenvolvimento tecnológico é tão variado e crescente que impossibilita a escola segui-lo na velocidade em que ele acontece (FAZENDA, 2013).

Assim, a aplicação da Abordagem STEAM através de projetos interdisciplinares, facilita a construção de conexões entre o conhecimento científico pré-adquirido em sala de aula e o mundo real. Nesta perspectiva, tais práticas quando aplicadas em estudos reais colaboram com a expansão de informações previamente introduzidas e favorecem a consolidação de novos conhecimentos (BACICH; HOLANDA, 2020).

Para o professor conduzir um trabalho interdisciplinar e investigativo dentro e fora das aulas é necessário que ele tenha um olhar para o estudante como um ser humano que possui desejos e limitações, e não somente um olhar para com o conteúdo a ser aplicado (HARDOIM et al., 2019).

Nessa vertente, o ensino pensado através da Abordagem STEAM pode ser eficaz, pois desenvolve o conhecimento a partir da integração entre áreas do conhecimento, de forma a contemplar o desenvolvimento de habilidades práticas, com a Engenharia e a Tecnologia; artística, com a Arte e aplicação dos conhecimentos teóricos, abordados nas áreas de Ciências e de Matemática (MACHADO; GOMES JÚNIOR, 2019). 
A realização de atividades interdisciplinares tem mostrado êxito através de reflexos significativamente positivos na promoção de uma visão ampla acerca das questões cotidianas por parte dos estudantes, pois elas estimulam o desenvolvimento de competências e habilidades descritas na Base Nacional Comum Curricular (BNCC) e respeitam seus limites (MACHADO; GOMES JÚNIOR, 2019).

$O$ desenvolvimento destas competências e habilidades, mais especificamente na área das Ciências da Natureza estão presentes na Base Nacional Comum Curricular (BNCC) e no Documento de Referência Curricular do Estado de Mato Grosso (DRC-MT). Assim, o objetivo deste artigo foi desenvolver um projeto interdisciplinar nos anos finais do Ensino Fundamental em uma escola pública a partir da Abordagem STEAM.

\section{MATERIAL E MÉTODOS}

Essa investigação é uma abordagem qualitativa, de natureza aplicada com características de pesquisa exploratória. Para Minayo (2001) o estudo qualitativo trabalha com o universo de significados, motivos, aspirações, crenças, valores e atitudes, o que corresponde a um espaço mais profundo das relações, dos processos e dos fenômenos que não podem ser reduzidos à operacionalização de variáveis, já a pesquisa exploratória delimita um campo de trabalho, podendo mapear as condições desse objeto (SEVERINO, 2014).

Esta análise foi realizada na Escola Estadual Deputado João Evaristo Curvo localizada no município de Jauru, região oeste de Mato Grosso e contou com a participação de seis professores que lecionam os componentes curriculares de Ciências da Natureza, Matemática e Arte no Ensino Fundamental (Anos Finais) e dezoito estudantes do $6^{\circ}$ e $7^{\circ}$ Ano da mesma escola.

Após aceitarem o convite para participar da pesquisa, os professores e os responsáveis pelos estudantes assinaram o Termo de Consentimento Livre Esclarecido (TCLE) aprovado pelo Comitê de Ética (CAAE) no 36391220.1.0000.5165, parecer ํㅜ.4.275.074.

Quanto aos procedimentos, a investigação é classificada como, bibliográfica, no formato de pesquisa ação (LAKATOS; MARCONI, 2011; SEVERINO, 2014). A pesquisa bibliográfica é desenvolvida com base em diversos materiais já elaborados e publicados, constitui-se especialmente por livros e artigos científicos. Utiliza-se de dados ou de categorias teóricas já trabalhadas por outros pesquisadores e devidamente registrados. A pesquisa ação visa intervir na situação, com vistas a modificá-la (SEVERINO, 2014).

Como instrumentos de coleta de dados foi utilizada a observação participante (OP) durante a construção e execução das ações do Projeto Interdisciplinar intitulado: Pandemia da COVID-19. A observação participante (OP) consiste na participação real do pesquisador com a comunidade ou grupo, ele se incorpora ao grupo, confunde-se com ele, ficando tão próximo quanto um membro do grupo (LAKATOS; MARCONI, 2011).

O processo de análise dos dados foi realizado através de Análise Documental Descritiva. Essa metodologia possui finalidade de produzir novas compreensões e fenômenos de natureza qualitativa e permite analisar e fragmentar textos originados de "documentos que ainda não tiveram nenhum tratamento analítico, que são ainda matéria-prima, a partir da qual o pesquisador vai desenvolver sua observação e análise" (SEVERINO, 2014, p. 131). 


\section{RESULTADOS E DISCUSSÃO \\ Aplicação da Abordagem STEAM através de Projeto Interdisciplinar}

Diante do cenário pandêmico vivenciado mundialmente desde o fim do ano de 2019 , essa pesquisa foi realizada virtualmente, assim como seguem descritos os relatos e discussões. Após a realização de uma formação docente com a participação de nove professores de uma escola pública localizada no município de Jauru, foi feita uma proposta de aplicação da Abordagem STEAM baseada em projetos que foi aceita por seis professores e o tema sugerido por eles foi: A pandemia da COVID-19.

Para a construção do projeto interdisciplinar, os professores selecionaram as competências gerais: (1) Conhecimento, (2) Pensamento Científico e Crítico, (4) Comunicação, (5) Cultura Digital e (9) Empatia e Cooperação para serem desenvolvidas.

Com as competências definidas, os professores e estudantes do $6^{\circ}$ e $7^{\circ}$ ano que estavam participando das atividades escolares síncronas através do google sala de aula - classroom $^{\circledR}$ no ano letivo de 2021, construíram e aplicaram a Abordagem STEAM através de um projeto interdisciplinar.

O modelo adotado foi o proposto por Bacich e Holanda (2020) em seu livro: "STEAM em sala de aula", modelo de Canvas para organizar as etapas com estudantes que será descrito a seguir.

\section{Pandemia da COVID-19 (características gerais da doença) - 6 Ano}

O projeto interdisciplinar intitulado: Pandemia da COVID-19 - características gerais da doença, proposto para $\circ 6^{\circ}$ ano, foi construído observando as competências e habilidades que os estudantes devem desenvolver de acordo com a Base Nacional Comum Curricular (BNCC) e o Documento de Referência Curricular do estado de Mato Grosso (DRC-MT) para o ano citado.

Neste contexto, o projeto realizado (Quadro 1) por 09 (nove) estudantes do 6은 Ano A, apresentou respostas às indagações: Como ocorre a infecção do vírus SarsCov-2 na célula humana e quais são as consequências de sua proliferação no organismo?

Para a realização das ações descritas no projeto, os estudantes foram divididos em três grupos.

QUADRO 1. Projeto interdisciplinar 6을. Ano.

\begin{tabular}{|c|c|}
\hline \multicolumn{2}{|c|}{ Projeto - $6^{\circ}$ ANO } \\
\hline \multicolumn{2}{|c|}{ A Pandemia da COVID-19-Características Gerais } \\
\hline \multicolumn{1}{|c|}{ Questão Norteadora } \\
\hline $\begin{array}{l}\text { Como ocorre a infecção do vírus Sars-CoV-2 na célula humana e quais são as } \\
\text { consequências de sua proliferação no organismo? }\end{array}$ \\
\hline (EF06CI05) & $\begin{array}{l}\text { Explicar a organização básica das células e seu papel como } \\
\text { unidade estrutural e funcional dos seres vivos. }\end{array}$ \\
\hline (EF06CI06) & $\begin{array}{l}\text { Concluir, com base na análise de ilustrações e/ou modelos (físicos } \\
\text { ou digitais), que os organismos são um complexo arranjo de } \\
\text { sistemas com diferentes níveis de organização. }\end{array}$ \\
\hline EF69AR35) & $\begin{array}{l}\text { Identificar e manipular diferentes tecnologias e recursos digitais } \\
\text { para acessar, apreciar, produzir, registrar e compartilhar práticas e } \\
\text { repertórios artísticos, de modo reflexivo, ético e responsável. }\end{array}$ \\
\hline (EF06MA33) & $\begin{array}{l}\text { Planejar e coletar dados de pesquisa referente a práticas sociais } \\
\text { escolhidas pelos alunos e fazer uso de planilhas eletrônicas para }\end{array}$ \\
\hline
\end{tabular}




\begin{tabular}{|c|c|}
\hline & $\begin{array}{l}\text { registro, representação e interpretação das informações, em } \\
\text { tabelas, vários tipos de gráficos e texto. }\end{array}$ \\
\hline & Objetivos de Aprendizagem \\
\hline $\begin{array}{l}\text { - Apresenta } \\
\text { - Exemplific } \\
\text { - Conhecer } \\
\text { - Demonstr } \\
\text { global, naci } \\
\text { - Compara } \\
\text { meses; } \\
\text { - Demonstr } \\
\text { - Conhecer } \\
\text { - Organizar }\end{array}$ & $\begin{array}{l}\text { rganização de uma célula animal; } \\
\text { estrutura de um vírus; } \\
\text { ocesso de replicação do vírus Sars-CoV-2 dentro da célula humana; } \\
\text { través de gráficos a proliferação do vírus Sars-CoV-2 em escala } \\
\text { estadual e municipal; } \\
\text { evolução da doença no estado de Mato Grosso nos últimos seis } \\
\text { ravés de material lúdico a organização interna do vírus; } \\
\text { ofilaxia da COVID-19; } \\
\text { stra sobre a infecção do vírus, sintomas e maneiras de prevenção. }\end{array}$ \\
\hline & Ações \\
\hline Etapa 01 & $28 / 06 / 2021$ a 09/08/2021 \\
\hline & $\begin{array}{l}\text { - Apresentar aos estudantes o conceito de vírus e a estrutura do } \\
\text { Sars-CoV-2; } \\
\text { - Construir modelo ilustrativo do vírus em maquete representando } \\
\text { como ele infecta e prolifera nas células. } \\
\text { - Realizar pesquisa sobre os principais sintomas da doença e } \\
\text { gravar um podcast com o resultado da pesquisa; } \\
\text { - Construir material ilustrativo sobre os meios de transmissão do } \\
\text { vírus; } \\
\text { - Produzir cartazes informativos sobre as maneiras de prevenção da } \\
\text { COVID-19; } \\
\text { - Pesquisar e construir gráficos em planilhas eletrônicas e } \\
\text { apresentador de slides sobre o avanço do vírus no mundo, no } \\
\text { Brasil, Mato Grosso e em Jauru; } \\
\text { - Construir perguntas para a realização de entrevista com um } \\
\text { profissional da Secretaria Municipal de Saúde abordando: } \\
\text { transmissão, sintomas e profilaxia da CoviD-19 e também } \\
\text { perguntas a uma pessoa que foi infectada pelo vírus; } \\
\text { - Entrevistar um profissional da Secretaria Municipal de Saúde } \\
\text { sobre o tema e uma pessoa que foi acometida pela doença. }\end{array}$ \\
\hline Etapa 02 & $10 / 08 / 2021$ \\
\hline & Resultado \\
\hline Apre & nunidade escolar o material \\
\hline
\end{tabular}

Fonte: Adaptado de Bacich e Holanda (2020)

Para Lorenzin (2020), o professor deve modificar as práticas pedagógicas, indo além do ensino tradicional, visando uma transformação na qual o estudante tenha experiências em trabalho em grupo e seja protagonista na construção do seu conhecimento. Nesse viés, os estudantes realizaram pesquisas sobre a pandemia na internet e na Secretaria Municipal de Saúde de Jauru-MT.

Durante três aulas de Ciências da Natureza, o professor apresentou aos estudantes o conceito de célula trazido por Gewandsznajder e Pacca (2018) no livro: Teláris: Ciências - 6을 através da plataforma virtual Meet ${ }^{\circledR}$ visando desenvolver as habilidades: (EF06CI05) explicar a organização básica das células e seu papel como unidade estrutural e funcional dos seres vivos; (EF06Cl6) concluir, com base 
na análise de ilustrações e/ou modelos (físicos ou digitais), que os organismos são um complexo arranjo de sistemas com diferentes níveis de organização.

Após a apresentação dos conceitos, os estudantes realizaram pesquisas na internet e no material didático sobre a organização celular e o funcionamento das principais organelas da célula animal. Em seguida, foi discutido em sala virtual a estrutura dos vírus e como ocorre a invasão dos mesmos nas células, enfatizando o Sars-Cov-2 que é o causador da COVID-19.

Com a pesquisa realizada, os estudantes construíram material ilustrativo sobre o vírus Sars-CoV-2 em meio digital e realizaram a gravação em vídeo sobre a sua organização. Para Uzunian (2020), o Sars-Cov-2 é um vírus de ácido ribonucleico (RNA) e seu material genético possui uma única molécula de RNA positivo. Este vírus contém mais de 30.000 (trinta mil) nucleotídeos, formados por uma ribose, uma base nitrogenada e um ácido fosfórico.

Além de explicar sobre a estrutura dos vírus, os estudantes pesquisaram e também gravaram material abordando os principais sintomas da COVID-19, destacando: síndrome gripal (SG), caracterizada por febre, tosse ou dor de garganta, coriza e dificuldade respiratória (NUNES et al., 2020), também foram discutidas as principais medidas para a prevenção da doença, dentre elas: uso de máscaras, distanciamento social e higienização das mãos com álcool ou detergente e também dos ambientes (NUNES et al., 2020).

Ao utilizar atividades investigativas em sua prática pedagógica o professor favorece o desenvolvimento de estudantes mais críticos, mais participativos e que buscam referências a serem problematizadas e compreendidas, além da interação social das propostas em pares ou grupos (PIRES, 2020).

Para Blanco (2020), ao realizar trabalhos na perspectiva da Abordagem STEAM os estudantes podem atingir excelentes níveis de proatividade e raciocínio lógico. Assim, em Matemática durante quatro aulas visando desenvolver a habilidade (EF06MA33) planejar e coletar dados de pesquisa referente a práticas sociais escolhidas pelos alunos e fazer uso de planilhas eletrônicas para registro, representação e interpretação das informações, em tabelas, vários tipos de gráficos e texto; o professor, trabalhou com a turma o conceito de gráfico (barras e colunas) e tabela, apresentado por Souza (2018) no livro didático: Matemática \& Tecnologia: 6ำ Ano, diferenciando tabela simples e de dupla entrada.

Com os objetos do conhecimento trabalhados, e a partir da pergunta norteadora os estudantes realizaram pesquisas sobre a quantidade de pessoas contaminadas pelo vírus Sars-Cov-2 no mundo, no Brasil, em Mato Grosso e em Jauru até a data de 30 de julho do ano de 2021. Com os dados coletados, os estudantes organizaram em tabelas os valores encontrados e inseriram estes, no vídeo final de divulgação do projeto.

De acordo com o Painel Coronavírus ${ }^{1}$, site do Ministério da Saúde que atualiza diariamente os casos de pessoas infectadas pelo vírus no Brasil e nos estados brasileiros, em 19 de setembro de 2021, cerca de 21.239.783 pessoas no país já tinham sido infectadas pelo vírus e cerca de 590.752 vieram a óbito.

Ao pesquisarem essas informações de forma ativa, os estudantes interagiram com o assunto estudado, ouvindo, dialogando, refletindo, fazendo e ensinando, tornando-se capaz de produzir conhecimento ao invés de recebê-lo de forma passiva (SEGURA; KALHIL, 2015).

$1 \quad$ Disponível em: http://covid.saude.gov.br 
Nessa perspectiva, no componente curricular de Artes, já com os conceitos sobre o vírus estudados em Ciências da Natureza e com os dados da pandemia discutidos em Matemática, o professor propôs a discussão do texto: Por dentro das artes visuais - Espaço e Materiais de Pougy \& Vilela (2018) - 6으 Ano. Para Lorenzin e Bizerra (2016) a Abordagem STEAM reconhece a importância das Artes no processo de aprendizagem e atribui a ela a devida relevância nas práticas criativas e reflexivas do ensino das ciências e tecnologias.

Após as reflexões os estudantes construíram em biscuit e em isopor (em suas residências) a estrutura do vírus Sars-Cov-2 (Figura 1), visando o desenvolvimento da habilidade (EF69AR35) identificar e manipular diferentes tecnologias e recursos digitais para acessar, apreciar, produzir, registrar e compartilhar práticas e repertórios artísticos, de modo reflexivo, ético e responsável.

FIGURA 1. Estudantes produzindo material sobre o Sars-CoV-2

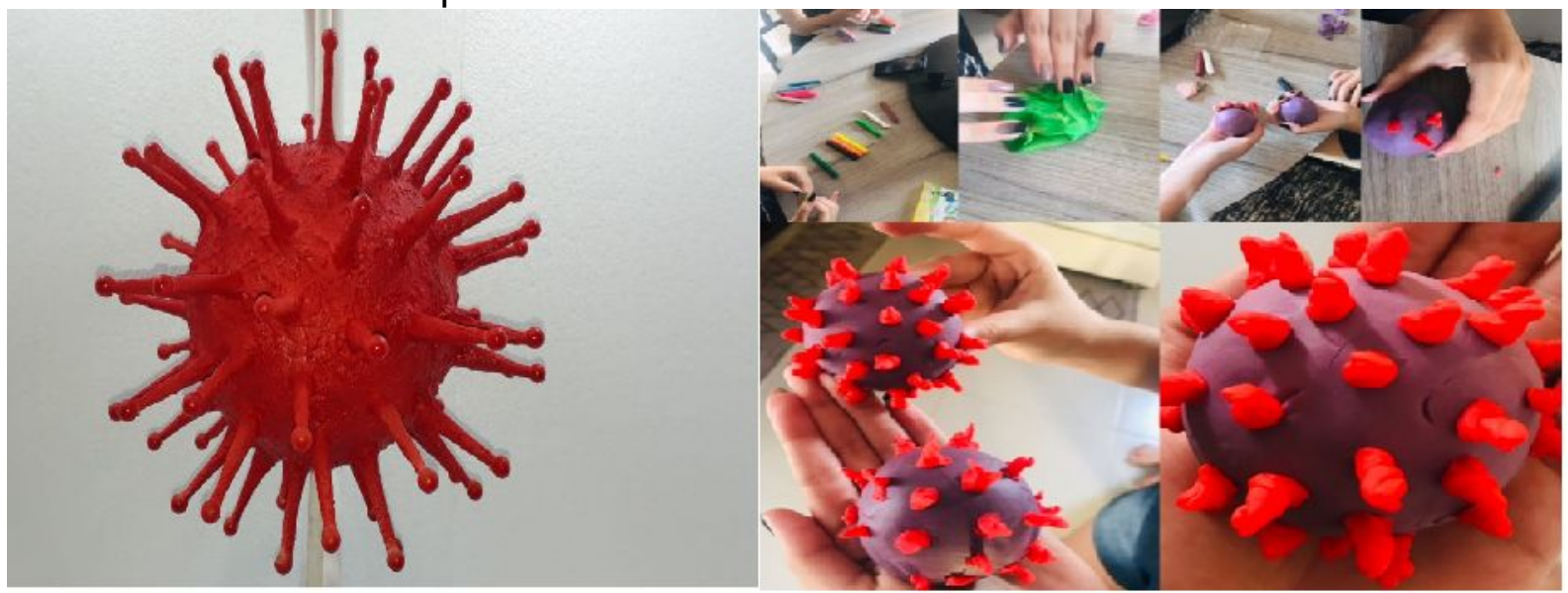

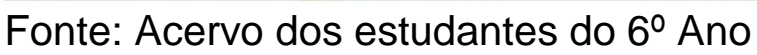

Juntamente com o professor construíram também perguntas para serem realizadas a dois entrevistados do projeto: um enfermeiro, representante da Secretaria Municipal de Saúde e uma pessoa que já foi infectada pelo Sars-Cov-2. Os estudantes enviaram as perguntas para os entrevistados através do aplicativo WhatsApp®

Após este material/dados serem recebidos e organizados, foram enviados para a edição e assim fizeram parte do vídeo orientativo sobre a COVID-19, publicado nas redes sociais da escola e no canal virtual da instituição no endereço: https://www.youtube.com/watch?v=aAbgCRhY-eM ${ }^{2}$.

A integração dos componentes curriculares com atividades que se complementaram no desenvolvimento das ações do projeto interdisciplinar, despertou nos estudantes o desejo de conhecer os conceitos científicos sobre a estrutura celular humana e a organização do vírus Sars-CoV-2 trabalhado nas aulas de Ciências da Natureza. Para que o estudante pudesse adquirir conhecimento holístico sobre o tema, ele foi apresentado também aos conceitos matemáticos de gráficos e tabelas, no qual a partir da pesquisa sobre o número de pessoas acometidas pela pandemia da COVID-19, puderam organizar esses dados e relacionar o conhecimento nos dois componentes curriculares.

2 No vídeo construído pelos estudantes, o vírus Sars-CoV-2 é mencionado como Novo Coronavírus, pois, em 2019 quando ele foi descoberto ele recebeu essa denominação. Quando o material foi gravado, esta ainda era a nomenclatura utilizada. 
Para Blanco (2020), é nesse ponto que a Abordagem STEAM se mostra eficiente, ou seja, através do desenvolvimento de ações, propõe que o ensino de Ciências e de Matemática se complementem utilizando a Engenharia e a Tecnologia para resolver problemas como proposto pelo projeto, pandemia da COVID-19.

Neste contexto integrativo, o envolvimento da Arte também é importante, pois através dela os estudantes puderam externar o conhecimento científico e matemático mediante a construção de materiais concretos e apresentar este conjunto a seus pares e comunidade local, com o vídeo produzido.

\section{A importância das vacinas no combate a COVID-19 - $7^{\circ}$ Ano}

O projeto desenvolvido pelo $7^{\circ}$ Ano enfocou a importância da vacinação no combate ao Sars-CoV-2 devido as especificidades das habilidades de Ciências da Natureza a serem desenvolvidas neste ano de ensino e também porque este componente curricular deve desenvolver no estudante a capacidade de enfrentar situações do cotidiano, com trabalhos em grupo, resolução de problemas individuais e coletivos (SEGURA; KALHIL, 2015), conhecendo e divulgando a importância da vacinação na família, grupo e comunidade escolar. Desde os primeiros relatos da proliferação do Sars-CoV-2 no mundo, os cientistas passaram a pesquisar medicamentos de controle e vacinas eficazes para combater o vírus (WHO, 2020).

Após muitos estudos, e quase um ano de pandemia, a Agência Nacional de Vigilância Sanitária, (órgão regulatório brasileiro que fiscaliza medicamentos, cosméticos entre outros), aprovou algumas vacinas produzidas por farmacêuticas conhecidas mundialmente. Dentre os imunizantes autorizados e ofertados pelo Plano Nacional de Vacinação do Brasil, estão: Covishield, Cominarty, Coronavac e Jansen (MACIEL; QUARESMA, 2021).

Mesmo com o controle rigoroso das agências e resultados comprovados através de publicações divulgadas nas principais revistas científicas do mundo, muitas pessoas têm-se negado a receber os imunizantes e o vírus Sars-Cov-2 continua se proliferando. Assim, o projeto do $7^{\circ}$ ano (Quadro 2), buscou responder as seguintes questões: Qual é a importância da vacinação completa no combate ao Sars-CoV-2? Como age no organismo as vacinas ofertas no Plano Nacional de imunização? Quantas pessoas já se vacinaram na cidade de Jauru?

QUADRO 2. Projeto interdisciplinar $7^{\circ}$ Ano.

$$
\text { Projeto }-7^{\circ} \text { Ano }
$$

A importância das vacinas no combate a COVID 19

Questão Norteadora

Qual é a importância da vacinação completa no combate ao Sars-CoV-2? Como age no organismo as vacinas ofertas no Plano Nacional de imunização? Quantas pessoas já se vacinaram na cidade de Jauru?

\section{Habilidades}

\begin{tabular}{|c|l|}
\hline (EF07Cl10) & $\begin{array}{l}\text { Argumentar sobre a importância da vacinação para a saúde } \\
\text { pública, com base em informações sobre a maneira como a } \\
\text { vacina atua no organismo e o papel histórico da vacinação para } \\
\text { a manutenção da saúde individual e coletiva e para a } \\
\text { erradicação de doenças. }\end{array}$ \\
\hline (EF07Cl10.1MT) & $\begin{array}{l}\text { Discutir a respeito da equidade na distribuição de vacinas entre } \\
\text { os municípios no estado e nas diversas regiões do país. }\end{array}$ \\
\hline (EF07MA36) & $\begin{array}{l}\text { Planejar e realizar pesquisa envolvendo tema da realidade } \\
\text { social, identificando a necessidade de ser censitária ou de usar }\end{array}$ \\
\hline
\end{tabular}




\begin{tabular}{|c|c|}
\hline & $\begin{array}{l}\text { amostra, e interpretar os dados para comunicá-los por meio de } \\
\text { relatório escrito, tabelas e gráficos, com o apoio de planilhas } \\
\text { eletrônicas. }\end{array}$ \\
\hline (EF69AR35) & $\begin{array}{l}\text { Identificar e manipular diferentes tecnologias e recursos digitais } \\
\text { para acessar, apreciar, produzir, registrar e compartilhar práticas } \\
\text { e repertórios artísticos. }\end{array}$ \\
\hline \multicolumn{2}{|c|}{ Objetivos de Aprendizagem } \\
\hline \multicolumn{2}{|c|}{$\begin{array}{l}\text { - Compreender o processo de produção e a importância das vacinas; } \\
\text { - Diferenciar a tecnologia empregada na produção das vacinas contra a COVID-19; } \\
\text { - Pesquisar os efeitos das vacinas autorizadas pela Anvisa contra a COVID-19. } \\
\text { - Reconhecer a importância da vacinação completa no processo de imunização; } \\
\text { - Pesquisar sobre as vacinas recebidas em Jauru, dosagem aplicada e grupos } \\
\text { contemplados; }\end{array}$} \\
\hline \multicolumn{2}{|r|}{ Accões } \\
\hline Etapa 01 & $28 / 06 / 2021$ a $09 / 08 / 2021$ \\
\hline Ações & $\begin{array}{l}\text { - Pesquisar a ação dos imunizantes autorizados pelas agências } \\
\text { reguladoras de saúde para o combate ao Sars-CoV-2; } \\
\text { - Construir material ilustrativo em powerpoint sobre as vacinas } \\
\text { autorizadas pela Anvisa no combate ao Sars-CoV-2, } \\
\text { exemplificando a diferença entre os imunizantes; } \\
\text { - Realizar pesquisa sobre o avanço da vacinação em escala } \\
\text { global; } \\
\text { - Construir gráficos apresentando um panorama mundial, } \\
\text { brasileiro, mato-grossense e jauruense sobre a aplicação da } \\
\text { primeira e da segunda dose das vacinas produzidas; } \\
\text { - Organizar perguntas para serem feitas ao convidado (a) da } \\
\text { Secretaria Municipal de Saúde sobre a vacinação contra a } \\
\text { COVID-19. } \\
\text { - Produzir um vídeo falando sobre a importância da imunização } \\
\text { completa. }\end{array}$ \\
\hline Etapa 02 & $10 / 08 / 2021$ \\
\hline \multicolumn{2}{|r|}{ Rest } \\
\hline
\end{tabular}

Fonte: Autores (2021)

Para desenvolver as ações, os professores reuniram-se com 09 estudantes do $7^{\circ}$ Ano através de plataforma virtual Mee ${ }^{\circledR}$ e juntos estabeleceram o cronograma com atividades integrativas de Ciências da Natureza, Matemática, Arte e Tecnologia. Para Lorenzin (2020), o trabalho com projetos interdisciplinares integra o conhecimento e a reflexão, onde associado ao autoconhecimento, à imaginação e a criatividade favorece a construção da aprendizagem a partir das ressignificações e aplicação de conceitos em situações reais.

Neste contexto, em Ciências da Natureza, durante quatro aulas no google ${ }^{\circledR}$ sala de aula, o professor apresentou a turma o conceito de vacina e sua importância, abordado nos textos construídos por Gewandsznajder e Pacca (2018) do livro, Teláris: Ciências: $7^{\circ}$ Ano, onde os autores enfatizam que as vacinas são os meios mais eficazes para a prevenção de doenças, pois elas estimulam o organismo na produção de anticorpos no combate aos antígenos. 
O professor realizou também um resgate histórico sobre as principais vacinas que estão disponíveis para a população e sua importância no combate às doenças, assim, trabalhou a habilidade (EF07Cl10) argumentar sobre a importância da vacinação para a saúde pública, com base em informações sobre a maneira como a vacina atua no organismo e o papel histórico da vacinação para a manutenção da saúde individual e coletiva e para a erradicação de doenças e também a habilidade do DRC-MT, (EF07Cl10.1MT) discutir a respeito da equidade na distribuição de vacinas entre os municípios no estado e nas diversas regiões do País.

Em seguida falou sobre o Sars-CoV-2 e a necessidade da vacinação para o seu controle, pois vacinas que estão autorizadas são produzidas para ensinar o sistema imunológico do corpo a reconhecer e bloquear com segurança o vírus que causa a COVID-19 (WHO, 2020).

Os estudantes foram divididos em grupos e realizaram pesquisas na internet sobre as vacinas autorizadas no Brasil. De acordo com Maciel e Quaresma (2021), a

- Coronavac - Produzida pelo laboratório Sinovac BioNtech utiliza o vírus SarsCov-2 inativo para induzir o organismo a produzir anticorpos.

- Cominarty@ - Produzida pelos laboratórios Pfizer e BioNtech, utiliza instruções genéticas (DNA e RNA) para que o corpo produza cópias de uma proteína viral (Proteínas Spike) e estimule a produção de anticorpos.

- Covishield e Jansen - A primeira produzida pela Universidade de Oxford e pela farmacêutica Astrazeneca e a segunda pela Jansen, farmacêutica da Jhonson \& Jhonson. As duas vacinas possuem a mesma tecnologia. São produzidas a partir de um vetor viral, adenovírus, sorotipo 26 (Ad26) que contêm pequeno segmento do genoma do vírus da COVID-19.

Com as informações sobre os imunizantes organizadas em slides, os estudantes gravaram em vídeo o resultado da pesquisa. Para Lorenzin (2020), ao interpretar as Ciências como atividade conectada às aplicações tecnológicas os conhecimentos científicos e cotidianos motivam a aprendizagem.

Em Matemática o professor trabalhou com os estudantes o desenvolvimento da habilidade (EF07MA36) planejar e realizar pesquisa envolvendo tema da realidade social, identificando a necessidade de ser censitária ou de usar amostra, e interpretar os dados para comunicá-los por meio de relatório escrito, tabelas e gráficos, com o apoio de planilhas eletrônicas, utilizando as definições trazidas por Souza (2018) no livro Realidade \& Tecnologia do $7^{\circ}$ Ano.

O professor também enfatizou a construção de gráficos de colunas, barras e de segmento. Demonstrou através do editor de planilhas eletrônicas como são feitos os cálculos e, em seguida, estabeleceu critérios para a busca de dados sobre a vacinação no combate a COVID-19 em escala global, nacional, estadual e municipal.

Para Coelho e Góes (2020), o desenvolvimento de projetos aplicando a Abordagem STEAM proporciona ao estudante experiências vivenciadas na resolução de problemas envolvendo a investigação, compreensão do pensamento científico, crítico e criativo. Assim, durante duas semanas os estudantes realizaram investigação, principalmente na internet no site: http://localizasus.saude.gov.br, com lapso temporal do início da vacinação contra o Sars-CoV-2 que no Brasil foi em 17 de janeiro de 2021 até o dia 16/08/2021.

De acordo com os dados do site http://localizasus.saude.gov.br, até o dia 16 de agosto de 2021 mais de 115 milhões de pessoas no Brasil tinham recebido alguma dose de vacina contra a COVID-19 e mais de quarenta e nove milhões de brasileiros $\left(43,15 \%\right.$ dos que tomaram a $1^{1}$ a dose $-2^{\underline{a}}$ dose) tinham recebido as duas doses de algum dos imunizantes ou ainda, dose única no caso do recebimento da 
vacina da Jansen. Em Mato Grosso e em Jauru, 38,83\% e 26,69\%, respectivamente, dos que tomaram a primeira dose ou a dose única apresentaram vacinação completa. No mundo, até aquela data, apenas $26,69 \%$ apresentavam o esquema vacinal completo.

Durante duas aulas os dados foram compilados e os gráficos construídos. Com a pesquisa realizada, os estudantes realizaram a gravação em vídeo dos dados encontrados (Figura 2).

FIGURA 2. Gravação dos dados sobre a imunização do Sars-CoV-2.

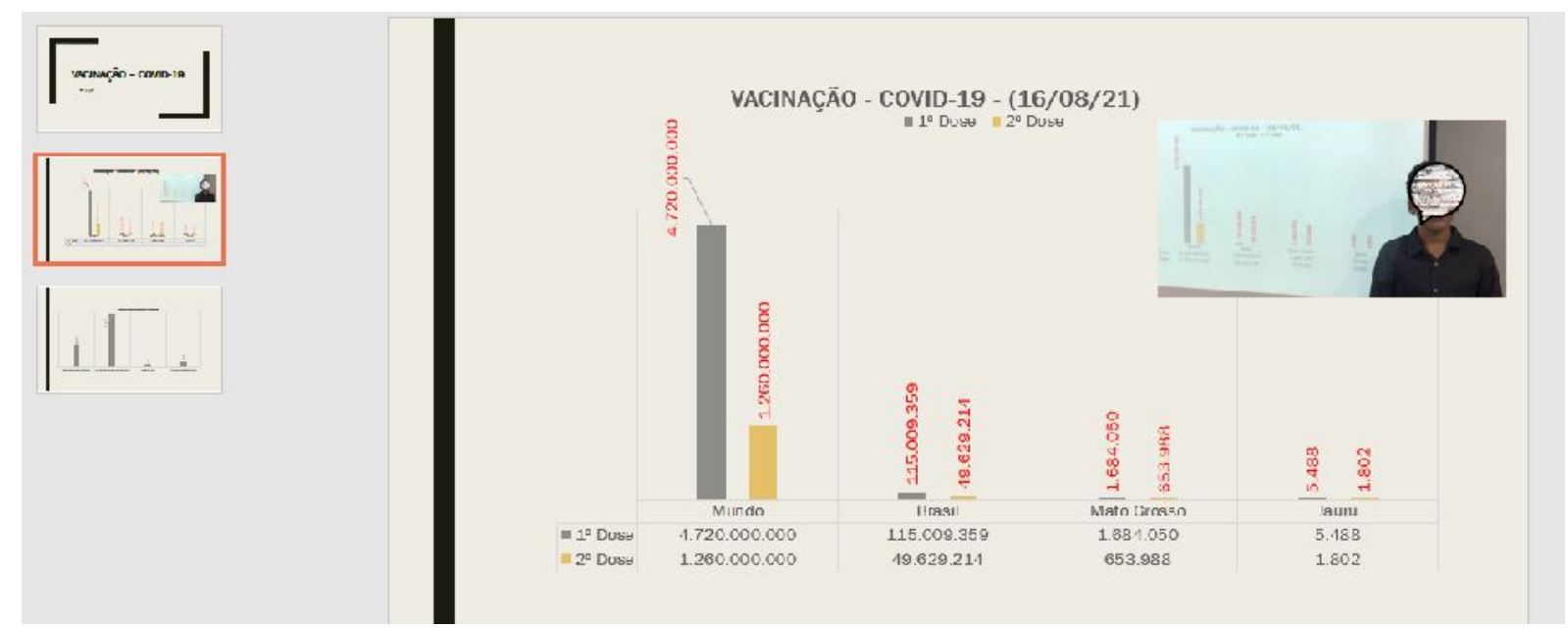

Fonte: Acervo dos estudantes do $7^{\circ}$ Ano

Para Lorenzin et al. (2018), a abordagem STEAM baseada em projetos que partem de problemas reais como a pandemia da COVID-19, possibilita a integração de objetos do conhecimento contextualizados das diferentes áreas de ensino, favorecendo o protagonismo do estudante na construção de seu conhecimento.

Assim, em Artes, durante duas aulas através da plataforma Meet ${ }^{\circledR} 0$ professor trabalhou com os estudantes a habilidade (EF69AR35) de identificar e manipular diferentes tecnologias e recursos digitais para acessar, apreciar, produzir, registrar e compartilhar práticas e repertórios artístico, através do texto de Pougy e Vilela (2018), linguagem audiovisual do livro didático: Teláris: Arte - 7ํㅗㅅ

O professor enfatizou a importância do enquadramento da câmera, diferenciando os diversos planos: conjunto, americano, médio, close-up ${ }^{3}$ (primeiro plano) e big close-up, bem como os movimentos da câmera, a importância da trilha sonora e da iluminação, a elaboração do roteiro e planejamento de cenas.

Com os conceitos trabalhados, os estudantes construíram as perguntas a serem realizadas ao responsável pela vacinação contra o Sars-CoV-2 no município de Jauru e as enviaram para o profissional da Saúde via aplicativo WhatsApp® Em seguida, observando as orientações recebidas nas aulas de Arte gravaram todo o material pesquisado em vídeo e disponibilizaram os dados através do endereço eletrônico: https://www.youtube.com/watch?v=cKkf9EThGZc ${ }^{4}$ a comunidade.

O professor ao trabalhar com temas reais como a pandemia da COVID-19, instiga o estudante a buscar respostas a resolução de problemas. Durante a

\footnotetext{
$3 \quad$ Tradução da autora

No vídeo construído pelos estudantes o vírus Sars-CoV-2 é mencionado como Novo Coronavírus, pois, em 2019 quando ele foi descoberto ele recebeu essa denominação. Quando o material foi gravado, esta ainda era a nomenclatura utilizada.
} 
pesquisa, foi possível verificar nas aulas online e no WhatsApp®

ão dos estudantes ao saberem que diversas pessoas da comunidade se recusaram a se imunizarem por motivos particulares, mesmo diante de uma doença que de acordo com a Organização Mundial de Saúde ${ }^{5}$ já matou mais de quatro milhões de seres humanos pelo mundo até outubro de 2021.

Conhecer as principais vacinas que combatem o Sars-CoV-2 foi importante para os estudantes, pois a partir deste conhecimento expandido em suas famílias e em forma de vídeo, diversas pessoas passaram a conhecer a importância da vacinação, e foi possibilitando a estas uma reflexão mais profunda sobre seus benefícios individuais e para a coletividade.

Nessa vertente, é importante destacar que a atuação dos professores foi fundamental, pois, para que a aprendizagem pudesse ocorrer efetivamente em todos os campos, foi necessário que eles conhecessem e desafiassem os estudantes durante o processo (BACICH; HOLANDA, 2020), especialmente no levantamento de dados sobre os casos acometidos pela doença.

Para Bacich e Holanda (2020) a aplicação da abordagem STEAM, exige planejamento articulado a contextos significativos para os estudantes, inserção de desafios de acordo com suas potencialidades e interesses, problematização e abertura para múltiplos caminhos com possibilidade de diferentes respostas.

\section{CONCLUSÃO}

Este artigo possibilitou uma análise sobre a aplicação da Abordagem STEAM no desenvolvimento das competências e habilidades descritas nos documentos oficiais orientadores do currículo da educação básica brasileira e mato grossense, BNCC e DRC-MT.

De acordo com a pesquisa as competências gerais da BNCC e do DRC-MT apresentam aspectos que a abordagem STEAM contempla, o que favorece ao estudante construir uma aprendizagem contextualizada, sendo ele o protagonista.

Este desafio que no início causou preocupação por causa da pandemia da COIVID-19, transformou-se em superação, pois ao analisar a construção das atividades pelos estudantes, é possível afirmar que o trabalho individual e em pequenos grupos realizado por eles contribuiu positivamente para confirmar os benefícios de uma educação ativa.

Nessa perspectiva, acreditamos que esse estudo possa contribuir com professores de Jauru, e escolas de Mato Grosso, do Brasil e de outros países, que estão ressignificando seus currículos com inserção de práticas ativas em sala de aula e ainda com pesquisas científicas sobre as competências e habilidades que os estudantes devem desenvolver através do ensino de Ciências da Natureza.

Assim, o estudante, ao vivenciar projetos STEAM, desenvolve autonomia na criação, na elaboração, na testagem de soluções para resolução de problemas, aprofundando conceitos e identificando dados relevantes que possam contribuir com a criação do produto final, como apresentado no projeto sobre a pandemia da COVID-19.

\section{AGRADECIMENTOS}

Os autores agradecem o apoio dos colaboradores professores e estudantes da Rede Pública de Ensino e da Rede de Saúde de Jauru-MT, assim como ao Programa de Pós-Graduação em Ensino PPGEn IFMT.

$5 \quad$ Disponível em: $\underline{\text { https://covid19.who.int }}$ 


\section{REFERÊNCIAS}

BACICH, L.; HOLANDA, L. (Orgs). STEAM em sala de aula: a aprendizagem baseada em projetos integrando conhecimentos na educação básica. Porto Alegre: Penso, 2020.

BLANCO, R. M. M de Matemática. IN. BACICH, L. HOLANDA, L. (Orgs). STEAM em sala de aula: a aprendizagem baseada em projetos integrando conhecimentos na educação básica. Porto Alegre: Penso, 2020.

COELHO, J. R. D.; GÓES, A. R. T. Proximidades e convergências entre a Modelagem Matemática e o STEAM. Revista Educação Matemática Debate, v.4, n.10, p.1-23, 2020. Disponível em: https://www.periodicos.unimontes.br/index.php/emd/article/view/2754.

DOI:10.46551/emd.e202045

FAZENDA, I. C. A. Desafios e perspectivas do trabalho interdisciplinar no ensino fundamental. In FAZENDA, I. C. A (Org.) Novos enfoques da pesquisa educacional. São Paulo: Cortez, 2010.

FAZENDA, I. C. A. Integração e Interdisciplinaridade no ensino brasileiro: efetividade ou ideologia. São Paulo: Edições Loyola, 2013.

GEWANDSZNAJDER, F. PACCA, H. Teláris: Ensino Fundamental Anos Finais Ciências: 6을. Año Paulo: Ática, 2018.

GEWANDSZNAJDER, F. PACCA, H. Teláris: Ensino Fundamental Anos Finais Ciências: 7º Ano. São Paulo: Ática, 2018.

HARDOIM, E. L. HARDOIM, T. F. L. NAKAMURA, C. R. HARDOIM, A. H. L. Educação científica inclusiva: Experiências interdisciplinares possíveis para o ensino de Biologia e Ciências Naturais empregando o método STEAM. Revista Latin American Journal of Science Education, v.6, n.1, p.1-5, 2019. Disponível em: http://www.lajse.org/may19/2019_12056.pdf

LAKATOS, E. M.; MARCONI, M. A. Fundamentos de Metodologia Científica. São Paulo: Atlas, 2011.

LORENZIN, M. Formação de professores: vencendo os desafios de implementação do STEAM. In. BACICH, L.; HOLANDA, L. (Orgs). STEAM em sala de aula: a aprendizagem baseada em projetos integrando conhecimentos na educação básica. Porto Alegre: Penso, 2020.

LORENZIN, M.; ASSUMPÇÃO, C. M.; BIZERRA, A. Desenvolvimento do currículo STEAM no ensino médio: a formação de professores em movimento. In. BACICH, L.; MORAN, J. (Orgs). Metodologias ativas para uma educação inovadora: uma abordagem teórico-prática. Porto Alegre: Penso, 2018.

LORENZIN, M. P.; BIZERRA, A. F. Compreendendo as concepções de professores sobre o STEAM e as suas transformações na construção de um currículo 
globalizador para o ensino médio. Revista da SBEnBio, n.9, p.3662-3673, 2016. Disponível em: https://sbenbio.org.br/revistas/renbio-edicao-9/

LÜCK, H. Pedagogia interdisciplinar: fundamentos teórico-metodológicos. Petrópolis: Vozes, 2013

MACIEL, E. S.; QUARESMA, F. R. P. Cadernos Educativos: vacinação contra a COVID 19. Palmas: UFT, 2021. Disponível em: http://download.uft.edu.br/?d=c4765d32-3d83-4d40-9c33-

568f61 cfaf05;1.0:Cadernos\%20Educativos\%20\%20vacina\%C3\%A7\%C3\%A30\%20contra\%20a\%20Covid-19.pdf

MACHADO, E. S.; GOMES JÚNIOR, G. Interdisciplinaridade na investigação dos princípios do STEM/STEAM education: definições, perspectivas, possibilidades e contribuições para o ensino de química. Revista Scientia Naturalis, v.1, n.2, p.4357, $2019 . \quad$ Disponível em: https://periodicos.ufac.br/index.php/SciNat/article/view/2492

MINAYO, M. C. S. O desafio do conhecimento: pesquisa qualitativa em saúde. São Paulo: Hucitec, 2001.

NUNES, V. M. A.; MACHADO, F. C. A.; MORAIS, M. M.; COSTA, L. A.; NASCIMENTO, I. C. S.; NOBRE, T. T. X.; SILVA, M. E. COVID-19 e o cuidado de idosos. Natal: EdUFRN, 2020.2 Disponível em: https://repositorio.ufrn.br/jspui/handle/123456789/28754

PIRES, M. P. O STEAM e as atividades experimentais investigativas. IN. BACICH, L. HOLANDA, L. (Orgs). STEAM em sala de aula: a aprendizagem baseada em projetos integrando conhecimentos na educação básica. Porto Alegre: Penso. 2020.

POUGY, E.; VILELA, A. Teláris: Ensino Fundamental Anos Finais: Arte - 6o Ano. São Paulo: Ática, 2018.

POUGY, E.; VILELA, A. Teláris: Ensino Fundamental Anos Finais: Arte - $7^{\circ}$ Ano. São Paulo: Ática, 2018.

SEGURA, E.; KALHIL, J. B. As metodologias ativas como proposta para o ensino de Ciências. Revista REAMEC, v.3, n.1, p.87-98, 2015. Disponível em: https://periodicoscientificos.ufmt.br/ojs/index.php/reamec/article/view/5308. DOI: 10.26571/2318-6674.a2015.v3., n1.p87-98.i5308.

SEVERINO. A. J. Metodologia do trabalho Científico. São Paulo: Cortez. 2014.

SOUSA, J. G.; PINHO, M. J. Interdisciplinaridade e Transdiciplinaridade como fundamentos da ação pedagógica: aproximações teórico-conceituais. Revista Signos, Lajeado, ano 38, n. 2, p.93-110, 2017. Disponível em: http://www.univates.br/revistas/index.php/signos/article/view/1606. DOI: http://dx.doi.org/10.22410/issn.1983-0378.v38i2a2017.1606 
SOUZA, J. Matemática: Realidade \& Tecnologia - 6ำ Ano. São Paulo: FTD, 2018.

SOUZA, J. Matemática: Realidade \& Tecnologia - 7ํAno. São Paulo: FTD, 2018.

UZUNIAN, A. Coronavírus Sars-CoV-2 e Covid-19. Jornal Brasileiro de Patologia e Medicina Laboratorial, v.56, p.1-4, 2020. Disponível em:

https://www.scielo.br/j/jbpml/a/Hj6QN7mmmKC4Q9SNNt7xRhf/?lang=pt. DOI:

https://doi.org/10.5935/1676-2444.20200053 